\title{
On Several Supervision and Control Measures to Improve the Quality of Equipment Installation in Substation
}

\author{
Pengfei Yin ${ }^{1, \text { a }}$, Bangyuan Huang ${ }^{2, b}$, Kai Tang ${ }^{3, c}$ \\ ${ }^{1}$ Xinjiang Electric Power Engineering Supervision Co., Ltd \\ ${ }^{2}$ Xinjiang Electric Power Engineering Supervision Co., Ltd \\ ${ }^{3}$ National network of Xinjiang Institute of Supervision Company \\ ${ }^{a}$ email, ${ }^{b}$ email, ${ }^{c}$ email
}

Key words: Substation Equipment Installation; Quality Control; Supervision Card; Standard Process; Drawings

\begin{abstract}
Xinjiang Electric Power Engineering Supervision Co., Ltd. (referred to as the company) from the supervision of quality control and quality control, explore the application of standardized supervision card, flexible use of drawings, equipment out of the box, the standard process inspection and other means of control and to further improve the ex ante, in the matter, after the supervision process quality control system, to strengthen the quality control of the main equipment in the substation installation process. The company through the application in Xinjiang three Santanghu 750 thousand volt substation, jijihu 750 thousand volt substation in engineering construction. It has effectively reduced the quality defects of the main equipment in the 750 thousand volt substation at the same time, and played a positive role in improving the quality of the field.
\end{abstract}

\section{Introduction}

Substation construction is a huge system engineering and construction quality has a direct impact on the construction of the transfer of production standards work, excellent construction quality can significantly reduce the operating cost of substation. The quality of substation engineering quality control directly affects the substation after the economy, safety and reliability of power supply. The construction stage is the final process of the substation project entity, and it is also the key stage to determine the final quality of the substation while the main substation equipment installation is the priority among priorities at the stage of construction, the quality of the installation of equipment or even directly affects the normal operation and safe and stable operation of substation. The substation is completed and put into operation, such as equipment installation quality problems are caused by equipment shutdown, heavy impact on the stability of power grid caused by large area blackout. Therefore, the quality of construction projects in the construction process control, it is extremely important. To improve the technical level of the substation equipment installation, it is necessary to pay close attention to the quality control of construction stage.

\section{General Idea}

At this stage, due to uneven design, construction, construction units factory level, the direct cause of the quality level of the substation construction or not. Through the analysis, the main factors affecting the installation quality of the main equipment of the substation are construction environment, construction equipment, construction methods, professional ability and the quality of equipment, such as the five aspects. Therefore, to strengthen the quality control of main equipment of substation safety process is to strengthen the five aspects of the above factors control. The company through the main substation equipment installation and construction research and exploration of the whole process, strengthen process control from key drawings, equipment out of the box, the standard process and key process supervision inspection and acceptance. In the three stages before, during and after the event to further strengthen the quality control, effectively 
improve the quality of the installation of the field equipment.

\section{Drawings Reviewing}

Outline drawings. Refers to the construction engineering drawings the construction units and design units to submit a comprehensive and detailed study. There are problems in the construction and unreasonable situation and itemized analysis review, review of the formation of record and two times improvement is an important activity feedback design institute. At present, due to tight deadlines, substation construction personnel generally lack of technical strength as a result of the construction site exists drawings, drawings of pre compression frequency not strict phenomenon caused by drawing more is a mere formality, not to advance quality control for. Through the analysis of drawing the problems at this stage, the company after careful analysis, take the following measures to improve the effectiveness of the drawings, the drawings and carding the development process (see Figure 2).

Measures Taken. Reasonable arrangement of construction drawing review plan. Supervision project department according to the construction schedule and reasonable organization of the site drawings review in the course of engineering construction. Before construction according to the professional, phased, combined with the actual situation of the project site, in advance to organize the review of construction drawings, and will review the comments in a timely feedback design units, not to catch up and compressed the drawing review time and frequency, not easy way and a number of professional organizations to review the drawing package.

Supervise and urge the construction unit to do the preliminary examination. In the organization of drawings, the project supervision department should supervise the construction project department carefully drawing the pre-trial work, records should strictly examine the construction drawings submitted by the Department of pre-trial review whether the in-depth and comprehensive coverage. In the case of necessity shall require the construction units send technical backbone to participate in drawing examination, in order to strengthen the Ministry of construction project drawings preliminary results.

Strengthen supervision unit drawings audit. This year, the company will be the construction process of the drawings audit as the focus of inspection and control projects, the project will increase the work of ministerial drawing review time and effort, from the standard process applications, the implementation of strong, quality control and other aspects of the disease control and other aspects of in-depth and detailed drawing review. For key projects, the company through the temporary hiring of other units outstanding personnel to enhance the supervision of the project Department of technical force, effectively promote the supervision of the project department to further improve the effectiveness of the audit results.

\section{Unpacking Equipment}

An overview of the equipments. The equipments refers to equipment manufacturers to the project site, the construction units to the box to check the presence of equipment and early detection of equipment problems and defects after processing equipment manufacturers feedback, to avoid unnecessary rework after installation and disputes. At this stage due to the project construction tasks, the equipment arrived at the scene out of the box is not timely, on-site product protection ineffective or out of the box inspection personnel in place is not complete, not detailed damage to equipment, the phenomenon of missing parts occurred. For this phenomenon, re sort and standardize the equipment inspection and acceptance process (see Figure 3), and made the following measures.

Take Steps. Engineering equipment arrived at the scene, the first time the project supervision department, construction materials, written notice to the owner, manufacturers and other construction units to contact the relevant personnel of the construction unit arrived at the scene to carry out inspection and acceptance, acceptance, follow the early early detection and early 
treatment to solve the issues of principle, requirements of the construction unit shall not be any reason to refuse to receive equipment and acceptance.

The acceptance process, and urge all units in accordance with the acceptance list of equipment, construction drawings and equipment (materials) order specification check equipment specifications, the number of matches, accessories and spare parts are complete without damage; Check the appearance of equipment without mechanical damage and deformation, paint intact, no corrosion; oil body equipment (such as tank) seal should be good, with oil transportation equipment, oil pillow, oil level should be normal, oil should be no leakage; No damage, defects and cracks of insulating ceramic and epoxy resin castings; Tank cover or bell cover flange and sealing plate connection bolts should be complete, strong and good, no leakage; dry equipment packaging and moisture facilities intact, no rain water immersion marks; Nameplate parameters, product size, shape, weight, lead direction, in accordance with the provisions of the contract requirements and relevant current national standards; Product fication, inspection certificate, factory test report, packing list and other documents complete.

In the process of acceptancspecie, the project supervision department according to the requirements of good acceptance of the whole process of collecting image data, supervise the construction project department to do the unpacking inspection record and sign retained all out of the box to confirm and collect good raw materials and spare parts. In case of damage, lack of parts, lack of information and so on, in a timely manner to contact the owner of the project department, material supply company to coordinate and solve. Out of the box after the acceptance of the equipment and materials to the Ministry of construction project is the person responsible for the custody and good security, dustproof, moistureproof, fire prevention, anti freezing, high temperature and other measures, the main vulnerable equipment (components) to move to the room. If there is any damage or missing, the construction unit shall be responsible for the handling of the.

\section{Standard Process}

Standard process overview. The standard process is the summary and the refinement of the State Grid Corporation of project quality management, process design, construction technology and construction technology and mature experience, effective measures and the formation of a series of achievements, with advanced technology, safe and reliable, affordable and convenient popularization, is the project for the construction process design and construction plan selection of construction technology, and other related work is an important basis for. Therefore, strictly do a good job in the process of the application of the standard process control and acceptance, to improve the overall level of equipment installation process also played a major role in the substation equipment. In order to further improve the application level of the standard process in combination of "basic measures" Power Grid Corp transmission project process management on the national standard, and formulate the application standard process approval process, and the application of the standard process in the model four approval system "and" application standard process inspection record form ", to a good effect on strengthening the standard process control from application field.

Take steps. the standard process in the model square acceptance refers to each site standard process for the first time after the completion of the construction project supervision department, the joint owners, design and construction of relevant professionals for the construction of the physical model of the common acceptance standard process. The parties in accordance with the standard technical requirements for on-site evaluation of the application effect, such as failure of construction units need to be further improved after re inspection process. Such as qualified construction units in the follow-up application needs to be strictly in reference to the acceptance model to carry out construction.

The project supervision department according to the design units to provide the application standard process list in advance to carry out the training work, completes the application standard process inspection plan. Each of the standards process used by the Quartet model acceptance by the 
project supervision department, in the construction process of the same type of other standard process in strict accordance with the approved sample to check and control the development process, the formation of application standard process inspection record form, the application effect of low in the model effect of the site, the written request of construction units according to a model rectification.

\section{Standardized Supervision Card}

According to the characteristics of the substation equipment installation phase, various complex points, to improve work personnel on-site supervision of blindness and randomness, with "comprehensive coverage and focus" as the idea of combing the various types of equipment installed in the process of inspection contents, inspection standards, inspection methods and control points, the supervision of equipment series standard for the installation of card, in the form of cards, including the installation of each type of equipment inspection points, so that one card in hand, work content, inspection methods, inspection standards, control points, check the situation. The effective work of the site supervision staff has played a substantial role in guiding the inspection efficiency and work quality, and promote the continuous improvement of the technical level of the field equipment installation.

Standardized supervision card template

\begin{tabular}{|c|c|c|c|c|c|c|c|}
\hline \multicolumn{8}{|c|}{ XXXX standardized supervision card } \\
\hline $\begin{array}{c}\text { Seria } \\
1 \\
\text { num } \\
\text { ber }\end{array}$ & $\begin{array}{c}\text { Inspectio } \\
\mathrm{n} \text { items }\end{array}$ & $\begin{array}{l}\text { Inspecio } \\
\text { n content }\end{array}$ & $\begin{array}{c}\text { Inspectio } \\
\mathrm{n} \\
\text { standard }\end{array}$ & $\begin{array}{c}\text { Inspectio } \\
\mathrm{n} \\
\text { method }\end{array}$ & $\begin{array}{c}\text { Supervis } \\
\text { ion } \\
\text { control } \\
\text { points }\end{array}$ & $\begin{array}{l}\text { Check } \\
\text { the } \\
\text { situati } \\
\text { on }\end{array}$ & $\begin{array}{l}\text { Closed loop } \\
\text { rectification }\end{array}$ \\
\hline & & & & & & & \\
\hline & & & & & & & \\
\hline & & & & & & & \\
\hline & & & & & & & \\
\hline & & & & & & & \\
\hline & & & & & & & \\
\hline & & & & & & & \\
\hline
\end{tabular}

\section{Concluding Remarks}

The company has been applied in Xinjiang three 750 thousand volt substation, Santanghu jijihu 750 thousand volt substation in the construction of the four aspects of the management and control measures. In the acceptance stage, the three and 750 thousand volt jijihu Santanghu equipment installation quality defects in article 300 within the same period, while Bachu, Akesu and other 750 thousand volt substation equipment installation quality defects were about 900. Comparison found that in the above four aspects to strengthen supervision and control measures, the substation main equipment quality defects reduced by $67 \%$, to improve the level of equipment installation quality has played a significant positive role in promoting.

\section{Reference}

[1] Hu Cheng.Project management[M].Beijing: Higher Education Press.

[2] Chunjin Huang, Research and application of quality management in engineering supervision 
[D]. Xi'an: Xi`an University of Architecture and Technology, 2007

[3] Jianguo Wen. Analysis and Research on quality control of construction project [D]. Xi'an: Xi an University of Architecture and Technology, 2007

[4] Huifang $\mathrm{Xu}$, Yujian Shen, Lifu Chen. Experience of engineering quality management [J]. Construction economy, 2001 (8)

[5] Guanghua Li, Minghui Bao. Game Analysis on the supervision process of electric power engineering [J]. Electric power construction, 2013 (01). 